Original Article

\title{
PAIN, ANXIETY \& FUNCTIONAL STATUS OF PATIENTS WITH LOWER LIMB FRACTURE AND DISLOCATION AFTER OPEN REDUCTION
}

\author{
Ambili Alphonse Thomas ${ }^{1} \&$ Fatima D'silva ${ }^{2}$ \\ ${ }^{1}$ Post Graduate, ${ }^{2}$ Principal \& Professor, Department of M edical Surgical Nursing, \\ Nitte Usha Institute of Nursing Sciences, Nitte University, Paneer, Mangalore, Karnataka, India. \\ Correspondence : \\ Fatima D'silva \\ Principal \& Professor, Department of M edical Surgical Nursing, Nitte Usha Institute of Nursing Sciences, \\ Nitte University, Mangalore - 575 018, Karnataka, India. \\ E-mail : ftds_1970@ rediffmail.com
}

\begin{abstract}
:
A descriptive-co relational study was conducted to assess severity of pain, level of anxiety and functional status of patients with lower limb fracture and dislocation after open reduction from $17^{\text {th }}$ September to $3^{\text {td }}$ Nov 2012. Purposive sampling technique was used to select the subjects for the study. Data was collected by using demographic proforma, Numerical Pain Rating Scale, Beck's Anxiety Inventory and Functional status rating scale. The findings of the study showed that out of sixty samples, majority were males $49(82 \%)$. M ajority of the subjects 53(88\%) were married. Nature of job revealed that 21 (35\%) were laborers. 27 (45\%) of the subjects had monthly income between 5001-8000 rupees. 32 (53.3\%) had no habits of smoking, alcoholism or tobacco chewing. The findings of the study revealed that on the first post-operative day the mean value of pain (8.70), anxiety (22.85) and functional status scores (49.20) was greater than the pain (1.70), anxiety (11.90) and functional status scores (3.453) of the tenth post-operative day. A significant association was found between functional status and age ( $p=0.043,0.05$ level of significance).No significant correlation was found between severity of pain, level of anxiety and functional status of these patients.
\end{abstract}

Keywords : Pain, anxiety, functional status, lower limb fracture.

\section{Introduction:}

Bones form the skeleton of the body and allow the body to be supported against gravity and to move and function in the world. Bone is not a stagnant organ. It is the body's reservoir of calcium and is always undergoing change under the influence of hormones. Parathyroid hormone increases blood calcium levels by leeching calcium from bone, while calcitonin has the opposite effect, allowing bone to accept calcium from the blood. ${ }^{1}$

A bone fracture is a medical condition in which there is a break in the continuity of Access this article online Quick Response Code

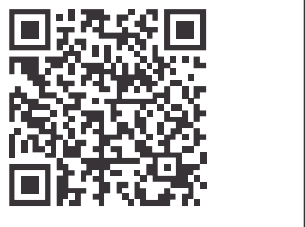
the bone. A bone fracture can be the result of a direct blow, repeated blows, a twisting force, disease that affects the strength of the bone, high force impact or stress, or trivial injury as a result of certain medical conditions that weaken the bones, such as osteoporosis, bone cancer, or osteogenesis imperfecta, where the fracture is then properly termed as a pathologic fracture. The main causes of fracture are traumatic or pathological. $80 \%$ of patients admitted in the orthopedic ward have injuries due to trauma. Most of these are due to RTA, others are due to domestic or work related injuries. India accounts for as high as 6 per cent of the world's RTAs, although it has 1 per cent of the world's vehicles. ${ }^{2}$

Fractures of the lower limb are common. They are often associated with considerable morbidity and a lengthy hospital stay. People with lower limb injuries may have difficulty, if working involves prolonged standing or walking, squatting, crouching, lifting heavy objects or work that involves weight bearing and twisting through the lower limbs ${ }^{3}$.

Patients with any orthopedic conditions often require 
more prolonged treatment than any other patients. Fixation in bed with inability to leave the bed for any purpose makes them rely on others even for their basic needs. Problems of musculoskeletal system have significant impact on persons, their family, society and also the country because it decreases the productivity of the individual ${ }^{4}$.

Research suggests there is a high prevalence of anxiety and depression amongst patients with chronic musculoskeletal pain, which can influence the effectiveness of rehabilitation programs. ${ }^{5}$ It is therefore important for clinicians including nurses involved in musculoskeletal rehabilitation programs to consider screening patients for elevated levels of anxiety and depression. Keeping this in mind the investigator was interested to assess the level of pain, anxiety and functional status of patient with lower limb fracture after open and closed reduction.

Materials and Methods:

Descriptive co relational research design was adopted in this study. Population comprised of patients with lower limb fracture and dislocation after open reduction admitted in the orthopedic wards of selected hospitals. Purposive sampling technique was used for the selection of 60 samples. Severity of pain was assessed by Numerical Pain Rating Scale; Level of anxiety by Beck's anxiety inventory (BAI) and Functional status by a rating scale. The reliability of the tools was assessed using Cronbachs alpha and it was found to be 0.75 for Becks anxiety inventory and 0.81 for the Functional status rating scale. The Numerical Pain Rating Scale was scored as follows:

1-3---- mild pain

4-6---- moderate pain

7-10----Severe pain

Becks Anxiety Inventory had 21 items and was scored as 0 ,

1, 2 and 3. Higher scores depicted severe anxiety. The Functional status rating scale had15 items and the levels of disability were scored asfollows:

$0-15$----No disability

16-30----Mild

31-45---M oderate

46-60----Severe
The data collection period extended from 17.09.2012 to 03.11.2012. Formal written permission was obtained from Hospital authority prior to data collection. An informed consent was taken from the patients admitted in orthopedic wards. Data was collected at two point of time i.e. on the first post-operative day and the tenth postoperative day using the same assessment tools.

\section{Results:}

Major findings of the study are discussed and presented below:

\section{Section 1: PartA - Description of sample characteristics}

Table-1: Percentage distribution of subjects based on demographiccharacteristics

$n=60$

\begin{tabular}{|c|c|c|}
\hline Demographic Variables & Frequency (f) & Percentage (\%) \\
\hline \multicolumn{3}{|l|}{ Age (in years) } \\
\hline 21-30 & 9 & 15 \\
\hline $31-40$ & 21 & 35 \\
\hline $41-50$ & 21 & 35 \\
\hline $51-60$ & 9 & 15 \\
\hline \multicolumn{3}{|l|}{ Gender } \\
\hline Male & 49 & 82 \\
\hline Female & 11 & 18 \\
\hline \multicolumn{3}{|l|}{ M arital status } \\
\hline Married & 53 & 88 \\
\hline Unmarried & 7 & 12 \\
\hline Widow / Widower & 1 & - \\
\hline Divorced & 1 & - \\
\hline \multicolumn{3}{|l|}{ Nature of job } \\
\hline Government employee & 6 & 10 \\
\hline Agriculture & 18 & 30 \\
\hline Laborers & 21 & 35 \\
\hline House hold worker & 9 & 15 \\
\hline Others..... & 6 & 10 \\
\hline \multicolumn{3}{|l|}{ M onthly Income (in rupees) } \\
\hline$<5000$ & 10 & 17 \\
\hline $5001-8000$ & 27 & 45 \\
\hline $8001-11000$ & 12 & 20 \\
\hline$>11000$ & 11 & 18 \\
\hline \multicolumn{3}{|c|}{ Recreational activities (in hospital) } \\
\hline Watching TV & 15 & 25 \\
\hline Reading books & 3 & 5 \\
\hline Listening music & 6 & 10 \\
\hline Talking with neighbor patient & ents 27 & 45 \\
\hline More than one option & 9 & 15 \\
\hline \multicolumn{3}{|l|}{ Habits } \\
\hline Smoking & 13 & 22 \\
\hline Alcoholism & 10 & 17 \\
\hline Tobacco chewing & 1 & 2 \\
\hline No habits mentioned above & 32 & 53 \\
\hline More than one habits & 4 & 7 \\
\hline
\end{tabular}


Section 1 : Part B - Clinical proforma on fracture assessment

Table - 2 : Percentage distribution of samples based on fracture assessment

$\mathrm{n}=60$

\begin{tabular}{lcc}
\hline Demographic Variables & Frequency (f) & Percentage (\%) \\
\hline Type of fracture & & \\
$\quad$ Road traffic accident & 48 & 81 \\
$\quad$ Fall & 12 & 19 \\
Extremity Involved & & \\
$\quad$ Right lower limb & 17 & 22 \\
$\quad$ Left lower limb & 43 & 78 \\
Bone involved & & \\
$\quad$ Patella & 17 & 28 \\
$\quad$ Tibia & 39 & 65 \\
$\quad$ Calcaneum & 4 & 7 \\
\hline
\end{tabular}

Section 2: Level of pain, anxiety and functional status assessed by using mean and standard deviation

Table: 3 Mean and standard deviation of pain, anxiety and functional status of patients with lower limb fracture or dislocation after open reduction

\begin{tabular}{lcc}
\hline VARIABLES & $\begin{array}{c}\text { FIRST POST } \\
\text { OPERATIVE DAY }\end{array}$ & $\begin{array}{c}\text { TENTH POST } \\
\text { OPERATIVE DAY }\end{array}$ \\
\hline & Mean \pm S.D & Mean \pm S.D \\
\hline Pain & $8.70 \pm 0.70$ & $1.70 \pm 1.14$ \\
Anxiety & $22.85 \pm 4.52$ & $11.90 \pm 29.10$ \\
Functional status & $49.20 \pm 4.57$ & $3.45 \pm 5.02$ \\
\hline
\end{tabular}

Section 3 : Association between severity of pain, level of anxiety and functional status of patients with selected demographic variables.

The study shows that the calculated $p$ value of Fisher's exact test for functional status and the variable age $(p=0.043$ ) is lesser than the $p$ value at $p<0.05$, hence the research hypothesis was accepted and it is concluded that there is a significant association between functional status and age.

Section 4 : Relationship between severity of pain, level of anxiety and functional status of patients with open reduction

No significant correlation was found between pain, level of anxiety and functional status of patients with lower limb fracture and dislocation. ( $p>05$ level of significance)

Discussion :

Section 1: Part a - Description of sample characteristics
M ajority 42 (70\%) were within the age group of 31-50 years and were males $49(82 \%)$. Similar findings were reported in a study conducted in Switzerland to assess the psychological distress and quality of life after orthopedic trauma. The study revealed that majority were men (59\%) and the mean age was found to be $44.5^{6}$. Contrary to the study few reviews have revealed higher incidence of lower limb fracture among females. ${ }^{7,8}$

\section{Part B - Clinical proforma on fracture assessment}

Majority 48 (81\%) of fracture were due to Road Traffic Accident. Similar findings were reported in a study conducted in Baltimore, U.S. to assess patient-oriented functional outcome after unilateral lower extremity fracture. The study revealed that $73 \%$ of the fractures were due to road traffic accident. ${ }^{9}$

\section{Section 2: Severity of pain, Level of anxiety and Functional status of patients with open reduction.}

On the first post-operative day the mean score of pain $(8.70 \pm 0.70)$, anxiety $(22.85 \pm 4.52)$, and functional status of fracture patients was comparatively greater than the mean scores of the tenth post-operative day for pain, anxiety and functional status respectively. $(1.70 \pm 1.14,11.90 \pm 29.10$ $3.45 \pm 5.02)$.Similar findings were reported in a study to determine the comparison of pain and its treatment in advanced dementia and cognitively intact patients with hip fracture. The study revealed that $40 \%$ of patients were having severe pain preoperatively which continued even in the post-operative period. ${ }^{10}$ Few studies have highlighted the intense severity of pain experienced by patients with lower limb fracture and recommended the need for early pain management through psychological or pharmacological intervention. ${ }^{11,12}$

In the present study $52(87 \%)$ of the patients with lower limb fracture had moderate anxiety. Several studies have reported the prevalence of anxiety and depression among patients with lower limb fracture. A study conducted in Jordan to assess the prevalence of anxiety and depression after lower limb fracture among 56 patients revealed the presence of anxiety and depressive symptoms in $37 \%$ and $20 \%$, respectively. ${ }^{13}$ The above findings suggest that health 
professionals need to implement interventions to decrease post-traumatic stress disorder, depression and anxiety to increase the quality of life following lower limb injuries.

The present study findings revealed $45(75 \%)$ of the subjects had severe functional disability on the first postoperative day .On the $10^{\text {th }}$ post-operative day none had severe disability but only $20(33 \%)$ had moderate disability. The findings are supported by another prospective study conducted on 367 patients with hip fracture revealed (44\%) had developed some functional dependency most commonly to bathing (42\%) and dressing (21\%). ${ }^{14}$

\section{Section 5: Association between severity of pain, level of anxiety and functional status of patients with open reduction with selected demographic variables.}

The present study revealed that on the first post-operative day there was a significant association between functional status and age ( $p=0.043)$ at 0.05 level of significance. The above findings indicated that age has an influence on functional status.

\section{References}

1. Shiel C. Fracture. [Serial on the Internet]. Medicine Net Inc.; 2007 [cited 2012 Feb 7]. Available from:MedicineNet.com.http:// www.medicinenet.com/fracture/article.htm.

2. Indian driving school. [Serial on the Internet].2010Dec [cited 2012 Sep 12]. Available on URL :http://www.indiandrivingschools.com/ accidents-on-indian-roads.html.

3. Wikipedia the free encyclopedia [serial on the Internet]. Bone fracture, [cited 2012 Feb 12]. Available from: http://en.wikipedia. org/wiki/Bone fracture

4. Pallant $F\rfloor$, Baily M C. Assessment of the structure of the hospital anxiety and depression scale in musculoskeletal patients. Health and quality of life outcomes. [Serial on the Internet]. 2005 Dec [cited 2012 Sep 12]; 82(3):82. Available on: http://www.hqlo.com/content /3/1/82

5. Epidemiology of Road Traffic Accidents in India-a Review of Literature. [Internet]. $2010 \mathrm{M}$ ay [cited $2012 \mathrm{Dec}$ 5]. [Serial on the Internet].2012 Nov [cited 2012 Dec 12]. Available on: http://www.srtt.org/ road traffic accidents.htm.

6. Mohit Bhandari, Jason W. Busse, Beate P. Hanson, Pamela Leece, Olufemi R. Ayeni,Emil H. Schemitsch Psychological distress and quality of life after orthopedic trauma: an observational study. Pubmed. [Internet]. 2008 Feb.[cited 2012 sep 12]. 51(1): 15-22. Available on http://www.ncbi.nlm.nih.gov/pmc/articles/PM C2386305. I

7. Kaye J A, Jick H. Epidemiology of lower limb fractures in general practice in the United Kingdom. [Internet]. 2004 Sep [cited 2013 Feb 11]. 10:368-374. Available on: http://injuryprevention.bmj.com /content/10/6/368. short

8. Ismail AA 1, Pye SR, Cockerill WC, Lunt M, Silman AJ, Reeve J, Banzer D, Benevolenskaya LI, Bhalla A, Bruges Armas J, Cannata JB, Cooper C Delmas PD,Dequeker J, Dilsen G, Falch JA, Felsch B, Felsenberg D, Finn

\section{Section 6: Relationship between severity of pain, level of anxiety and functional status of patients with open reduction.}

The study findings revealed that there is no relation between severity of pain, level of anxiety and functional status of patients with open reduction. Contrary to the present study a study conducted in Taiwan revealed a positive correlation between post-traumatic stress disorder and depression $(r=0.70, P<0.001)$ and between post-traumatic stress disorder and anxiety $(r=0.57$ $P<0.001$ ), and a negative correlation between posttraumatic stress disorder and quality of life $(r=0.47$, $P<0.001)^{15}$

\section{Conclusion:}

The study calls for strengthening supportive and educative care for reducing pain and anxiety and thus improving the functional status of patients with lower limb fracture. Better management makes a difference in the lives of those in need and will be a fulfilling role for many nurses as a care giver.

JD, Gennari C, Hoszowski K, Jajic I, Janott J, Johnell O, Kanis JA, Kragl G, Lopez Vaz A, Lorenc R, Lyritis G, Marchand F, Masaryk P, M atthis C Miazgowski T, Naves-Diaz M, Pols HA, Poor G, Rapado A, Raspe HH, Reid DM, Reisinger W, Scheidt-Nave C,Stepan J, Todd C, Weber K, Woolf AD, O'Neill TW.. Incidence of Limb Fracture across Europe: Results from the European Prospective Osteoporosis Study. [Internet]. 2002 Jun [cited 2013 Feb 11]. 13(7): 565-571. Available on: http://link.springer.com/article/10.1007\%2Fs001980200074?LI=true

9. MacKenzie EJ 1, Burgess AR, M cAndrew M P, Swiontkowski M F, Cushing $B M$, deLateur BJ, Jurkovich GJ, Morris JA Jr.. Patient-oriented functional outcome after unilateral lower extremity fracture. Pubmed. [Internet]. $1993 \mathrm{M}$ ay.[cited 2012 sep 12]. 7(5):393-401. Available on : http:// www.ncbi.nlm.nih.gov/pubmed/8229375

10. Morrison RS, Siu AL. A comparison of pain and its treatment in advanced dementia and cognitively intact patients with hip fracture. Pubmed. [Internet] 2000 Apr. [cited 2012 Sep 12]. 19(4):240-8. Available on: http://www.ncbi.nlm.nih.gov/pubmed/10799790.

11. Castillo RC, MacKenzie EJ, Wegener ST, Bosse MJ. Prevalence of chronic pain following limb threatening lower extremity trauma. Pubmed. [Internet] 2006 Jun [cited 2012 Sep 12]. 124(3):3219.Available on: http://www.ncbi.nlm.nih.gov/pubmed/16781066.

12. Wong EM, Chan SW. The pain experience and beliefs of Chinese patients who have sustained a traumatic limb fracture. Pubmed. [Internet]. 2008 Apr. [cited 2012 sep 12]. 16(2):80-7. Available on http://www.ncbi.nlm.nih.gov/pubmed/18519058.

13. Ziad M Hawamdeh MZ, Othman S Y, and IbrahimAl.Assessment of anxiety and depression after lower limb fracture in Jordanian patients. Pubmed[Internet]. 2008 Jun [cited 2013 Feb 12]. 4(3): 627-633. Available on: http://www.ncbi.nlm.nih.gov/pmc/articles /PMC2526369/ 
14. Cree M, Carriere KC, Soskolne CL, Suarez-Almazor M. Functional dependence after hip fracture. Pubmed. [Internet]. 2001 Oct [cited 2012 Sep 12]. 80(10):736-43. Available on : http://www.ncbi. nlm.nih.gov/pubmed/11562555

15. Wang CH, Tsay SL, Bond AE. Post-traumatic stress disorder, depression, anxiety and quality of life in patients with traffic-related injuries. Pubmed. [Internet]. 2005 Oct. [cited 2012 Sep 12]. 52(1):22-30. Available on: http://www.ncbi.nlm.nih.gov/pubmed/16149977. 